\title{
Discordant segregation of Xq28 markers and a mutation in the L1 gene in a family with $\mathrm{X}$ linked hydrocephalus
}

\author{
Monique Jouet, Lisa Strain, David Bonthron, Susan Kenwrick
}

\begin{abstract}
$X$ linked recessive hydrocephalus is the most common hereditary form of hydrocephalus. Genetic analysis indicates that the majority of cases are caused by mutations in a single gene in $\mathrm{Xq} 28$, recently identified as the gene for neural cell adhesion molecule L1. Genetic heterogeneity for this disorder was suggested following the description of a single large pedigree where $X$ linked hydrocephalus showed lack of linkage to Xq28 markers flanking the L1 gene. Mutation analysis in this family shows a single base pair deletion within the coding sequence of the $\mathrm{L} 1$ gene that would result in truncation of the mature protein. The nature of the mutation and its segregation with the disease through the pedigree indicate that it is the cause of $\mathrm{X}$ linked hydrocephalus in this family. These results are at odds with data obtained through segregation of alleles for markers flanking the L1 gene. Somatic and germline mosaicism is the most plausible explanation for these data, which also provide further evidence for genetic homogeneity of $X$ linked hydrocephalus.

( $\mathcal{}$ Med Genet 1996;33:248-250)
\end{abstract}

Key words: X linked hydrocephalus; Xq28 markers; L1 gene.

$\mathrm{X}$ linked recessive hydrocephalus is characterised by enlarged cerebral ventricles, mental retardation, spastic paraplegia, and, frequently, flexion deformities of the thumbs. ${ }^{1}$ Genetic linkage analysis has placed the gene for this disorder within Xq28. ${ }^{2}$ Recently we and others showed that $\mathrm{X}$ linked hydrocephalus and the related disorders MASA syndrome (mental retardation, aphasia, shuffling gait, and adducted thumbs) and spastic paraplegia type 1 (SPG1) result from mutations in the gene for neural cell adhesion molecule L1. ${ }^{3-11}$ Linkage data indicate that $\mathrm{X}$ linked hydrocephalus is genetically homogeneous. ${ }^{12-15}$ One exception was reported by Strain et $a l^{16}$ where two recombination events were observed between Xq28 markers that flank the L1 locus and the disease gene within a single pedigree (fig 1A). Repeated sampling and DNA fingerprinting were used to eliminate the possibility of sample misidentification, and thus the existence of a second gene for $\mathrm{X}$ linked hydrocephalus was suggested. Germinal mosaicism, a higher than usual recombination rate, or a chromosomal rearrangement in Xq28 could also explain these data and in view of these possibilities mutation analysis of the L1 gene was undertaken.

The 28 exons of the $\mathrm{Ll}$ gene from subject 19 (fig 1A) were screened using SSCP (single strand conformation polymorphism) and heteroduplex analysis ${ }^{6}$ and a single mobility shift observed for exon 23. Sequencing showed deletion of a single adenosine at position 3088 within the coding sequence ${ }^{17}$ (fig 2 ). The consequence of this mutation for L1 protein structure is illustrated in fig 3. A frameshift would lead to insertion of 72 new amino acids after amino acid 1029 of the mature protein and premature termination owing to creation of a downstream stop codon (UGA). Truncation of the protein would occur before the transmembrane domain, eliminating the potential for normal cell surface expression of L1.

This mutation was most easily visualised by heteroduplex analysis which was therefore used to show complete segregation of the deletion with the disorder within the pedigree (fig 1B). Heteroduplexes are visible for the two affected boys and four obligate carrier females, whereas none of six healthy sons of carrier mothers has the mutation. This includes the two healthy brothers (9 and 14) who had previously been shown to have inherited the same Xq28 haplotype as their carrier sisters for markers flanking the L1 gene (fig 1A). One possible explanation for the genetic results obtained with this family is gonadal mosaicism of subject 3. However, using DNA from blood samples obtained on two separate occasions, this person was repeatedly identified as a somatic carrier of the deletion.

Two lines of evidence indicate that the mutation identified in the $\mathrm{Ll}$ gene causes the disorder in this family. Firstly, the mutation segregates with the disease despite discordant segregation of alleles for flanking markers. Secondly, the nature of the mutation is similar to that observed in other families with severe $\mathrm{X}$ linked hydrocephalus. We have identified three additional mutations in three independent families that would result in truncation of the L1 protein before the transmembrane domain ${ }^{6}$ (unpublished observations). All three families represent the severe end of the clinical spectrum observed for this disorder.

An explanation is required for the discordant genetic data described for this family. One possibility is the occurrence of double re- 

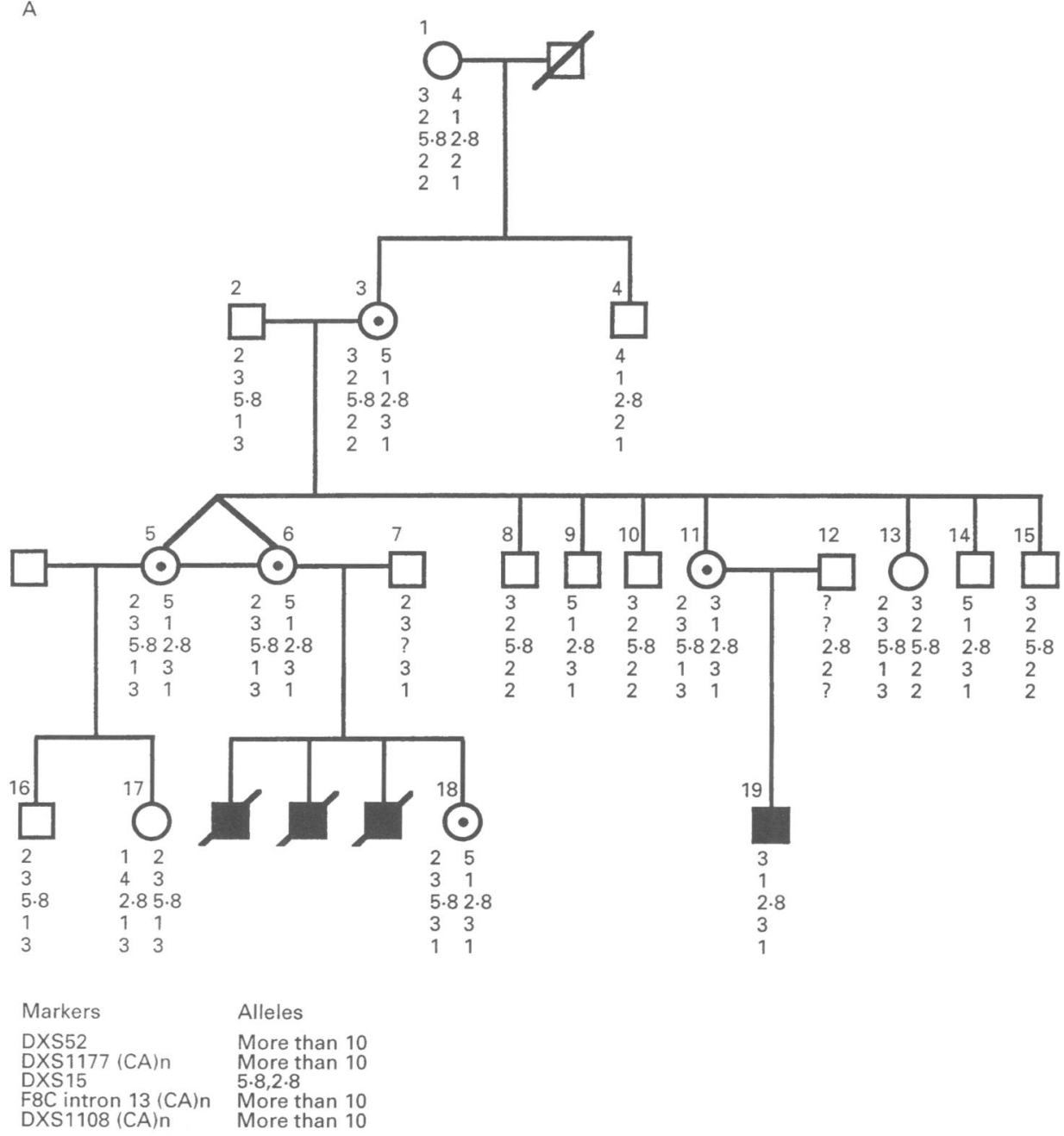

B

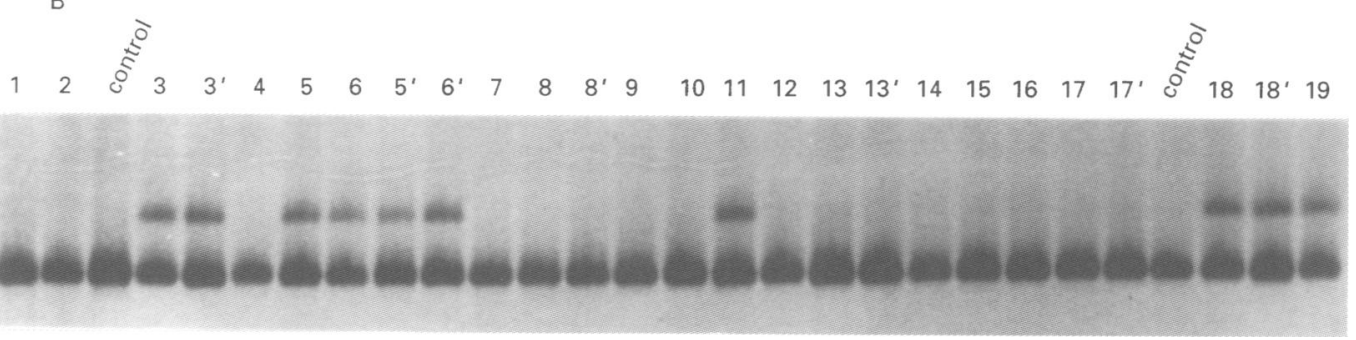

Figure 1(A) Genetic analysis showing that subjects 9 and 14 have inherited the same haplotype for markers flanking $L 1$ as carrier females and affected boys (L1 lies between DXS15 and F8C). Data for DXS52, DXS15, and F8C are from Strain et al. ${ }^{16}$ Data for DXS1177 and DXS1108 were derived for this report and confirm the original observations. (B) Segregation of the mutation throughout the pedigree as shown by heteroduplex analysis. The presence of the upper heteroduplex band is diagnostic of the presence of the 1 bp deletion.

combination events between Xq28 polymorphic markers DXS52 and F8C. The genetic distance between F8C and DXS52 is approximately $1 \%$ recombination. ${ }^{18}$ The probability of two recombination events within this interval is very small and would have to have occurred twice to account for the haplotypes of subjects 9 and 14. A further unlikely explanation is that local rearrangement of L1 in this family has displaced L1 from its flanking loci which could be addressed by multicolour FISH analysis. The most parsimonious and likely explanation is that subject 3 is a somatic and germinal mosaic for the deletion owing to mutation in early embryogenesis and, as a result, has contributed the same haplotype, with a mutation, to carrier daughters 5,6 , and 11 , and without a mutation to healthy sons 9 and 14. This hypothesis is supported by the observation that there has clearly been a new mutation in the genesis of subject 3 as all haplotypes inherited by affected or carrier subjects are grandpaternal. Furthermore, combined somatic and germinal mosacism has been well documented previously. ${ }^{1920}$

Whatever the explanation for the disparity, these data have a bearing on genetic counselling of this family and provide further evidence for the genetic homogeneity of $\mathrm{X}$ linked hydrocephalus. 
Family $\mathrm{H} 16$

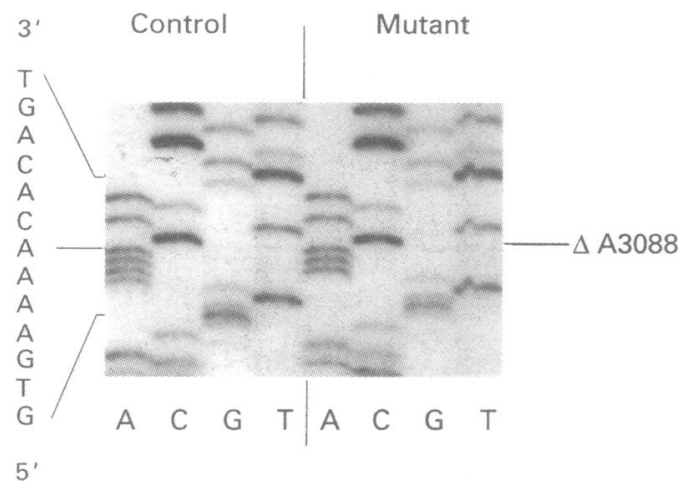

Figure 2 Sequence analysis of exon 23 from patient and healthy subject DNA. Exon 23 was amplified with primers $G 39$ and $g 40$ and primer $G 39$ was used for sequencing.

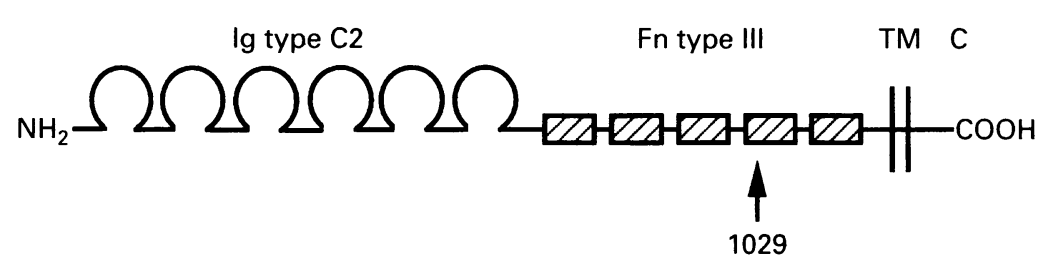

Figure 3 Structure of the L1 protein showing immunoglobulin type C2 (IgC2), fibronectin (Fn) type III, transmembrane (TM), and cytoplasmic (C) domains. The position of amino acid 1029 is indicated by an arrow.

MJ and SK are supported by the Medical Research Council.

1 Willems PJ, Brouwer OF, Dijkstra I, Wilmink J. X-linked hydrocephalus. Am $\mathcal{f}$ Med Genet 1987;27:921-8.

2 Willems PJ, Dijkstra I, Van Der Auwera BJ, et al. Assignment of X-linked hydrocephalus to Xq28 by linkage analysis. Genomics 1990;8:367-70.
3 Rosenthal A, Jouet M, Kenwrick S. Aberrant splicing of L1CAM mRNA associated with X-linked hydrocephalus. Nature Genet 1992;2:107-12.

4 Jouet M, Rosenthal A, MacFarlane J, Donnai D, Kenwrick $\mathrm{S}$. A missense mutation confirms the L1 defect in Xlinked hydrocephalus (HSAS). Nature Genet 1993;4:331.

5 Van Camp G, Vits L, Coucke P, et al. A duplication in the LICAM gene associated with X-linked hydrocephalus. Nature Genet 1993;4:421-5.

6 Jouet M, Rosenthal A, Armstrong G, et al. X-linked spastic paraplegia (SPG1), MASA syndrome and X-linked hydrocephalus result from mutations in the $\mathrm{L} 1$ gene. Nature Genet 1994;7:402-7.

7 Vits L, van Camp G, Coucke P, et al. MASA syndrome is due to mutations in the neural cell adhesion gene L1CAM. due to mutations in the neural

8 Coucke P, Vits L, Van Camp G, et al. Identification of a $5^{\prime}$ splice site mutation in intron 4 of the LICAM gene in an X-linked hydrocephalus family. Hum Molec Genet 1994;3 671-3

9 Jouet $M$, Kenwrick S. Gene analysis of L1 neural cell adhesion molecule in prenatal diagnosis of hydrocephalus. Lancet 1995;345:161-2.

10 Jouet $M$, Moncla A, Paterson J, et al. New domains of neural cell-adhesion molecule L1 implicated in X-linked hydrocephalus and MASA syndrome. Am 7 Hum Genet 1995;56:1304-14.

11 Ruiz J, Cuppens H, Leguis E, et al. Mutations in two families with X-linked complicated spastic paraplegia, MASA syndrome and HSAS. $\mathcal{F}$ Med Genet 1995;32:549-52.

12 Willems PJ, Vits L, Raemaekers P, et al. Further localization of X-linked hydrocephalus in the chromosomal region of X-linked hydrocephalus in the chrom

13 Serville F, Lyonnet S, Pelet A, et al. X-linked hydrocephalus: clinical heterogeneity at a single gene locus. Eur $\mathcal{F}$ Pediatr 992;151:515-18

14 Lyonnet S, Pelet A, Royer G, et al. The gene for X-linked hydrocephalus maps to Xq28, distal to DXS52. Genomics 1992;14:508-10.

15 Jouet M, Feldman E, Yates J, et al. Refining the genetic location of the gene for X-linked hydrocephalus within Xq28. I Med Genet 1993;30:214-17.

16 Strain L, Gosden CM, Brock DJH, Bonthron DT. Genetic heterogeneity in X-linked hydrocephalus: linkage to markers within Xq27.3. Am f Hum Genet 1994.54:236-43.

17 Hlavin ML, Lemmon V. Molecular structure and functional testing of human L1CAM. Genomics 1991;11:416-23.

18 Fain PR, Kort EN, Chance PF, et al. A 2D crossover-based map of the $\mathrm{X}$ chromosome as a model for map integration. Nature Genet 1995;9:261-5.

19 Bröcker-Vriends AHJT, Briët E, Dreesen JCFM, et al. Somatic origin of inherited hemophilia A. Hum Genet 1990; 85:288-92.

20 Raghunath M, Mackay K, Dalgleish R, Steinmann B. Genetic counselling on brittle grounds: recurring osteogenesis imperfecta due to parental mosaicism for a dominan mutation. Eur f Pediatr 1995;154:123-9. 